\title{
Entre Jacob e Narciso, o desespero e a redenção na poética de Murilo Mendes
}

\author{
Maria Marta dos Santos Silva Nóbrega (UFCG)
}

\begin{abstract}
RESUMO: A partir de poemas de As metamorfoses e A poesia em pânico, o trabalho analisa como a poética de Murilo Mendes atualiza os mitos de Jacob e Narciso quando busca resgatar sua auto-imagem. Os mitos ressurgem como forma de desmascarar e recriar as bases da criação poética muriliana. O trabalho noturno de Jacob em seu combate árduo com Deus até receber o emblema da libertação através do novo nome é revitalizado pelo poeta ao travar uma luta com a palavra buscando-lhe a plenitude do sentido. Na atualização do mito de Narciso, tem-se um ser poético debatendo-se nas tensões simbólicas do texto em procura de imagens de si e do mundo. Assim, mito e modernidade se articulam para que a poesia dê conta da autoconsciência desesperada do autor que busca incessantemente restaurar e redimir a poesia.
\end{abstract}

PALAVRAS-CHAVE: Murilo Mendes, Mito, Jacob, Narciso.

ABSTRACT: Based on poems in As Metamorfoses e A poesia em pânico, the work analyses the poetics in Murilo Mendes brings up to date the myths of Jacob and Narcissus as the seeks to rescue his self-portrait. Jacobs's night struggle during his hard fight with God, until he receives the liberation emblem through the new name, is revived by the poet as he engages in a battle with the word, searching for the fullness of sense. In bringing up to date the myth of Narcissus, there is the poetic being struggling with the symbolic tensions of the text, as he searches for the images of himself and the world. Thus, myth and modernity are joined so that poetry accounts for the desperate self-consciousness inside the author, who incessantly seeks to restore and redeem poetry.

KEYWORDS: Murilo Mendes, myth, Jacob, Narcissus. 
Abordar a obra de Murilo Mendes como uma poética do desespero e da redenção exige bastante esforço posto que o sentido de cada um dos termos não é perceptível de forma translúcida. $\mathrm{O}$ vocábulo desespero provém de dis-sperare e engloba a idéia de não confiar, perder as esperanças. Pode, portanto, ser entendido como tudo o que desconcerta, desune, separa e se opõe.

A nossa primeira hipótese é que o desespero enquanto estruturador da poética de Murilo Mendes coloca-se imaginariamente como uma necessidade que impulsiona o poeta a indagar pela sua identidade histórica e a vivenciar, a partir do eu, o drama de sua experiência vital. Necessidade plasmada na afirmação de brasilidade e universalidade pretendida pelos modernistas brasileiros. Nessa perspectiva, o imaginário poético do autor desenvolve-se em torno de uma expressão lírica que intenta buscar, no caos, a essência e a ordem ocultas na realidade circundante.

Já o vocábulo redenção, etimologicamente, vem do latim redimere e significa adquirir de novo, tirar do poder alheio. Um novo sentido que se pode extrair do termo é o de reunião de realidades opostas de tal forma que elas permaneçam juntas. Assim, em Murilo, a partir do desconserto provocado pelo desespero, o poeta assume a posição demiurgo de redentor, de criador e organizador de todo um Universo.

A idéia de mundo como desespero é responsável pela fragmentação do real e Murilo Mendes explora até a exaustão esta temática. Ao intercalar a consciência entre o eu e o mundo, o autor passa a ver as coisas como imagens descontínuas que a mente tenta desesperadamente harmonizar num todo coerente. A partir desta ausência de esperança, o poeta encontra, na tristeza, a força de sua poética. Poética de dissonância, pois a partir das causas do desespero, o eu constrói a redenção da poesia, posto que não há mais "tentação".

Em Murilo, os mitos de Jacob e Narciso ressurgem como forma de refletir e refratar, de desmascarar e recriar as bases estruturais da criação poética. Assim, a criação tende a ser reafirmada através do impulso do poeta ao vitalizar a poesia. $\mathrm{O}$ trabalho noturno de Jacob em seu combate árduo com Deus até receber, ao raiar do dia, o emblema da libertação através do novo nome é revitalizado pelo poeta que trava uma luta com a palavra buscando-lhe a plenitude do sentido. 
Tal como acontece com Jacob, o homem moderno está sempre sob o ataque e uma ameaça de morte que vem do exterior, ao mesmo tempo que, em seu interior, experimenta um enfrentamento não menos estafante entre o instinto de morte e a aspiração à vida, entre o espírito de mentira e o espírito de verdade; para reintegrar o espírito, é preciso passar pelas provas de uma iniciação, ao termo da qual o homem poderá 'pôr-se de pé', receberá um novo nome, como Jacó que renasceu chamando-se Israel (COUFFIGNALL, In. BRUNEL: 1977, p. 515-51)

$\mathrm{O}$ arquétipo de Jacob, herói consciente e duelador, trabalhando incessantemente pelo seu ideal, que nos interessa aproximar dos empenhos e impasses de alguma poesia de Murilo, que por sua vez inscreve-se na práxis da lírica moderna, a poesia da consciência vigilante, crítica e auto-reflexiva.

Agora, outra questão se põe: que tem a ver a poesia lírica moderna e mais precisamente a de Murilo Mendes com este mito de Jacob? Diríamos, desde já, que a forma arquetípica desse mito de resistência apresenta-se como um dos substratos simbólicos que justificam o acontecer poético nos conturbados tempos modernos, moldando a sensibilidade e a dramaticidade da auto-referência poética diante da obliteração enquanto totalidade significativa.

Ao voltar-se para si, buscando a sua face, a poesia moderna também busca reconstruir uma imagem do mundo, ou melhor, ela reflete e ao mesmo tempo refrata os impasses fundamentais do homem. Ao lutar com a palavra, antes que chegue a aurora da revelação poética, o poeta adquire consciência do seu ato diante do mundo. Ato que é uma forma de resistência e transcendência; uma busca que é também destino, ponto de chegada, ponto de encontro e reencontros.

Nesse contexto, o poema manifesta-se como um lugar privilegiado, fecundo de faces e falas diversas, pois a ponte da leitura que conduz ao mundo do fazer e do existir humanos, o mundo da história, é a mesma que conduz esse mundo de volta ao seu interior, ou seja, ao interior do poema. Fecha-se, assim, um círculo estranho no qual a linguagem, que deveria traduzir o universo humano, encena diante de si a própria existência. Homem e poesia se fundem, se confundem na metapoesia moderna, como 
Jacob tornou-se uma fusão de Esaú e Jacob na busca de um sentido - Israel, o poeta moderno, busca construir um significado para a vida.

Assim, poderíamos dizer que a poesia lírica, sob esse signo do eterno retorno do mesmo, reflete o drama de Jacob, ou seja, a ascensão e queda da linguagem humana, atuando nos limites da representação do mundo e da auto-referência (fala e afasia), buscando uma imagem de mundo nos abismos de suas imagens e miragens.

Há na lírica moderna, uma linguagem, como o próprio homem, compelida a se reelaborar a se renomear, a confrontar seus valores em ritmo e lutas alucinantes. Uma linguagem pejada de símbolos e espantos, de buscas e vazios, que "tanto desce como sobe...", como se pode ver em "Novíssimo Jacob":

\section{NOVÍSSIMO JACOB}

Antes de eu nascer tu velavas sobre mim

E mandaste teu anjo substituir minha mãe morta

Ele me continha quando eu corria à beira mar

Ou quando me debruçava sobre o abismo,

Cantava serestas e acalantos

Para aplacar minhas horas de pedra.

Às vezes uma vasta sombra atravessa os dias:

E de noite eu ouvia claramente os passos do serafim

Perderem-se nas estrelas do céu.

Mais tarde uma mulher ao meu lado

Tinha um esboço de asas nas espáduas

E na minha alma diminuíam os cuidados do tempo.

Manda-me de novo teu anjo

A fim de lavar as minhas chagas,

A fim de refrescar a minha boca:

Há dias em que nem mesmo tua palavra nos sustém.

É preciso que eu te veja nos menores detalhes,

É preciso que eu seja não só eu, também tu.

E que encare o sofrimento como um céu aberto,

E tua luz descendo e subindo sobre mim.

(Tempo e Eternidade, PCP.,p., 251)

A própria divisão do poema em dois momentos já sugere o desterro existencial do poeta e sua desarticulação representativa. Neste poema, o vazio inicial - ausência do místico - que ronda o texto constitui o drama existencial que envolve o eu lírico. A substancialidade desse vazio é flagrante nos tempos verbais da primeira estrofe, todos no pretérito: "velavas", "mandaste", "continha", "corria", "debruçava", "cantava", "atravessava", "ouvia", "perderem-se", "tinha", "diminuíam". Tal recurso estilístico 
reforça um drama corpóreo-existencial que o poeta persegue através da face textual: uma imagem de mundo escorregadia que faz voltas em si, mas ao mesmo tempo projeta a consciência ativa que busca a transcendência no interior da própria crise existencial.

A figura mística - o anjo e depois a mulher - transformou a angústia do poeta órfão em um concerto com "serenatas e acalantos", reforçando assim o caráter transcendental da linguagem poética elaborada em "dias que nem mesmo tua palavra (do místico) nos sustém”. O esvaziamento da vida alvitra o esvaziamento do discurso poético. Bloqueadas, a vida e a linguagem poética, o poeta faz o concerto com os despojos que lhe restaram - as chagas -, ou seja, a opção de viver e de fazer poemas, desejando voltar a ver o místico "nos mínimos detalhes". Não fosse essa opção consciente pelo reaparecimento do anjo, a sede pelo mistério e pela mística, o poema estaria para sempre perdido no sem-sentido, na impertinência do discurso frente às "horas de pedra".

A emergência dramática que impulsiona o desejo de "encarar o sofrimento como um céu aberto", sugere que a poesia lírica moderna foi condenada a ter como totalidade em seu horizonte expressivo apenas o fragmentário que marca o seu corpo. O poema "Novíssimo Jacob" dramatiza esse antagonismo, pois sabe o poeta, em seu exercício textual, que as linhas entre o efêmero e o eterno, a parte e o todo, são tênues. Onde se situar nesse trajeto? Nas angústias da existência em chagas e sede, ou na "luz descendo e subindo" sobre o poeta? Para responder a essas perguntas, o poeta, em "Novíssimo Jacob", apresenta-se como o ser que busca no espaço metalinguístico a sua realização e revelação poética.

Tal qual Jacob encontrou razões para sua existência na luta com o anjo, assim procede o poeta ao vislumbrar a "luz descendo e subindo" sobre si. A dualidade expressa pela imagem verbal "descendo e subindo" sugere a complexidade do processo literário, em que o criador parte de uma atmosfera caótica, porém extremamente fértil e dá ordem ao seu universo poético.

No poema "O poeta futuro", o eu lírico confessa-se "o homem sereno, a síntese de todas as raças, o portador da vida" que "saiu de tanta luta e negação e do sangue espremido" para construir o sentido que justifique a vida. Não só justifique, mas o faça 
prosseguir, sempre em transformação, ainda que este caminho seja árduo e o instigue a transformar "o aço de sua espada/ em penas que escreverão poemas consoladores".

Outra aproximação do poeta com o arquétipo de Jacob, pode ser vista no poema "O Pastor pianista". O texto, imbuído de forte imagística surrealista, apresenta a figura do poeta-pastor como um novíssimo Jacob apascentando pianos que, por sua poesia, leva à divindade o "antigo clamor do homem.

Ao analisar este poema, Antonio Candido enfatiza que o texto provoca um efeito de surpresa ante o inesperado: ao propor uma poesia pastoril, são seres inanimados pianos - que o poeta apascenta. De acordo com o crítico, este efeito sugere uma "poética da ausência”, em que as palavras inesperadas preenchem os vazios deixados pelo que, eventualmente, o leitor esperaria.

Em "A Criação e o Criador" - poema que abre o "Livro Segundo" de As Metamorfoses - o poeta se faz novo Jacob, lutador, capaz de despertar, com sua magia verbal, a noite, o sono do poema obscuro, dando-lhe "essência, corpo," vida.

Considerando que o ato criador é um processo, sua primeira dimensão implica na imprevisibilidade. O poema tem o tom de uma profissão de fé marcada pela aventura de quem mesmo, tendo se preparado cuidadosamente para uma jornada poética a fim de dar essência ao poema, não sabe, o poeta, o caminho no qual é lançado, posto que, vê-se perseguido pelo próprio poema. O poema, antes dependente do poeta, agora apresentase autônomo, personificado, incomoda o poeta e deve voltar "ao pó de onde proveio". Tal como Jacob combate com seu criador e busca uma autonomia, o discurso metalinguístico de "A criação e o Criador" sugere a luta do poeta com as palavras, ao ponto de desejar adormecer o poema e vê-lo reduzido à sua essência primeira: o pó.

Já com relação ao arquétipo de Narciso, veremos que Murilo atualiza a força expressiva do mito ao buscar sua auto-imagem, a consciência do ser poético - latente e manifesto - no espelho da linguagem textual. No confronto do poeta com o arquétipo de Narciso delineia-se o problema da crescente perda de identidade e integridade que subjaz aos padrões individuais da vida moderna. 
A construção da imagem poética (o pathos), em alguns textos murilianos, represa as águas que banham ou refletem o arquétipo do belo Narciso. Ao cruzar o mito de Narciso com a poesia de Murilo Mendes, sobressai, com grande vitalidade simbólica, uma das faces cruciais da poesia moderna, a consciência metalinguística inerente ao ato criador. Uma metalinguagem que é fruto, sobretudo, da crise de valores do mundo moderno que afetou o próprio caráter representativo da linguagem. Ou seja, busca da identidade expressiva como forma de resistência aos padrões existenciais da modernidade.

O arquétipo mítico de Narciso, ressurge não apenas como símbolo de contemplação e fruição do seu próprio ser, mas sobretudo como signo que busca a verdadeira identidade, o pleno (re)conhecimento de si. Dessa forma, a poesia de Murilo Mendes caracteriza-se tanto pela busca do reflexo do eu, das imagens do ser e do mundo codificados no texto, como também pelo desvelamento do eu do reflexo, ou seja, o ser do poema (linguagem e forma) a mirar-se na própria mirada do poeta. Vejamos "Poema visto por fora":

O espírito da poesia me arrebata

Para uma região sem forma onde passo longo tempo imóvel

Num silêncio de antes da criação das coisas.

Súbito estendo o braço direito e tudo se encarna:

O esterco novo da volúpia aquece a terra,

Os peixes sobem dos porões do oceano,

As massas precipitam-se na praça pública.

Bordéis e igrejas, maternidades e cemitérios

Levantam-se no ar para o bem e para o mal.

Os diversos personagens que encerrei

Deslocam-se uns dos outros, fundam uma comunidade

Que eu presido ora triste ora alegre.

Não sou Deus porque parto para Ele,

Sou um deus porque partem para mim.

Somos todos deuses porque partimos para um fim único.

(A poesia em pânico, $\mathrm{PCP} ., \mathrm{p} ., 285$ )

Esse texto nos lança num universo onde as imagens se desdobram e se confundem, escondendo o ponto de partida, a imagem verdadeira. $\mathrm{O}$ texto reflete uma plena e ousada consciência do salto metalinguístico que quer capturar o senhor da linguagem, o poeta, no ser de linguagem, o poema. Vê-se aqui o ir e o vir do discurso 
poético entre os espaços existenciais do real e do simbólico. É um jogo de espelhos próprio da arte moderna, que atrai para a sua órbita tanto a transfiguração do real em linguagem como a transmutação da linguagem em realidade intrínseca, que subsiste a partir da sua própria base simbólica.

"Poema visto por fora" além de apontar o espaço anterior à criação, traz a vida investida no cenário do poema, no ato da linguagem que se forma para formar o homem e o mundo. O homem que expõe a sua consciência para que atinja o outro, a consciência do poeta que baila no palco de sua comunidade.

O braço direito que se estende, "tudo se encarna" e constrói o espaço existencial em sua plenitude é uma imagem da própria escritura; o texto poético, palco da manifestação de si mesmo, do poeta e de seus personagens, é também palco da confluência de mundos: do humano e do divino. O poeta constrói uma cena de reflexos cambiantes na qual ora funde, ora confunde as imagens representativas dele e de seu mundo, com as imagens do próprio poema.

A força que arrebata o poeta para fora do texto é o desejo narcísico do autoconhecimento. Essa mirada narcísica busca construir, a partir de referenciais internos, um espaço positivo para a existência em meio à "região sem forma" de um mundo que ameaça imobilizar o poder criador.

A exemplo do que ocorre nesse poema, grande parte da obra de Murilo Mendes traz o estigma de auto-referência refletida na estruturação metalingüística, sobretudo, na emergência simbólica do texto. A dimensão narcísica ganha, na poesia de Murilo Mendes, uma relevância expressiva na própria imagem poética. Nesse sentido, o caráter narcísico impõe-se como arquétipo mítico que busca dar conta de questões fundamentais do escritor e da escritura, ou seja, a busca de autoconhecimento num mundo caótico, desprovido de referenciais que assegurem a plena manifestação do ser em sua integridade individual. Cabe ao poeta encontrar esses referenciais, buscá-los a partir do interior do seu próprio ser simbólico, e do ser de linguagem, o poema.

Não basta, como o inocente Narciso, olhar-se no espelho para se encontrar. Nesta mirada para dentro de si mesmo, o poeta deve ser um decifrador de enigmas, um operador metalingüístico que penetre no reino sagrado da palavra original, a qual, na 
modernidade, se é criadora, também, desconfia, questiona. É uma palavra portadora da consciência existencial, ainda que essa existência se apresente vazia de sentido.

Já na proposta do poema "Beira-mar", poderíamos dizer, que há a busca de um caminho que leve ao lago de Narciso, um lago cujas águas possam refletir imagens do ser - do ser do poeta e do ser da linguagem. Podemos observar, já a partir das várias afirmações de busca por respostas, que os caminhos que levam ao autoconhecimento estão bloqueados. Há trevas, posto que as luzes são ambíguas. O enigma da esfinge não corresponde à sua natureza; a consciência projeta-se na indefinição do som das ondas alteradas pelas idas e vindas. Há uma total perda dos referenciais simbólicos que poderiam conduzir ao pleno exercício da vida. Conseqüentemente, o ser não mais encontra a sua identidade, deslocado que está do seu tempo-espaço vital, local de integração do ser consigo mesmo e com o mundo circundante.

A “esfinge prepara lentamente/ o avesso de sua resposta", e obriga o eu lírico a internalizar a contradição e construir a sua trajetória poética. O poeta, com o poema, deve encontrar o seu espaço significante, a sua razão de ser, no meio da crise de representação que abala os alicerces do mundo moderno, numa luta incessante contra o caos da ilegitimidade da resposta ou mesmo do apelo às ondas.

Em outro poema, "Conhecimento", o centramento da consciência existencial do ser é mais ostensivo, denso e dramático. Parte-se o espelho de Narciso: em seu lugar, surge o drama de uma crise de identidade que tende a imobilizar o ser no campo de forças de uma questão fundamental - "Quem sou eu? - para sua integridade existencial. Apesar de o ser encontrar respostas, ao repetir a pergunta no quinto verso é como se não houvesse caminho de volta desse cenário apocalíptico onde o poeta indica "ao navio de poetas o caminho do pânico", que ameaça o futuro diante da perda das próprias referências primordiais: "a sombra ambulante de meus pais", "o cérebro deixado em pasto aos bichos".

Mas o caminho de volta ao enigma e às imagens perdidas, sabe o poeta, é o percurso do próprio poema, com suas formas instauradoras de símbolos e signos ativos da consciência existencial. Assim, em sua ânsia de identidade, de referências simbólicas 
vitais, ao estender "os braços para separar o tempo", o poeta passa a sentir o fluir temporal como uma possibilidade de eternizar o instante.

O desespero que acomete o eu lírico em "Conhecimento" se condensa numa só questão: "Quem sou eu? Essa é a pergunta que a poesia de Murilo Mendes persegue dentro desse universo simbólico do arquétipo de Narciso. Essa pergunta, de um lado, modula a dramática busca de identidade do poeta, e, de outro, a visão imanente e autoreflexiva do poema. Os dois (poeta e poema), articulados esteticamente, apagam as fronteiras entre o ser e o reflexo. A natureza de cada um apresenta apenas a sua face no intercâmbio com o outro. Narciso não existe sem sua imagem, e esta não subsiste sem aquele. Daí porque é capital ao poeta e à poesia moderna a questão básica do eu em sua integridade simbólica, o drama da perda e da busca de referências que permitam o reencontro consigo mesmo e com o mundo como imagem. Qual Narciso enlouquecido, poeta e poema desconfiam das imagens refletidas nas plácidas superfícies do tempo unificado, separa os tempos e mergulha nas violentas águas da existência, num embate colossal do ser consigo mesmo e com o seu tempo, sua História.

No arquétipo mítico de Jacob, conforme foi atualizado pela poesia de Murilo Mendes, vimos a busca de materialização do sentido poético e existencial dentro de uma ordem redundante das possibilidades do ser e de manifestar-se do poeta e do poema. $\mathrm{O}$ texto é marcado pela articulação de uma escada-palavra metalinguística que possibilita a ascensão e queda da palavra poética num movimento incessante em busca de sua expressividade. Ao assumir esta forma de ser, a poesia, no seu movimento de subir e descer, transcende as margens do nonsense e instaura o sentido existencial no processo ascendente e descendente infinito. Torna-se existência e resistência. Universaliza-se. Redime-se.

$\mathrm{Na}$ atualização do mito de Narciso, viu-se um ser poético debatendo-se nas tensões simbólicas do texto em busca de imagens de si e do mundo. A visão narcísica, característica de toda poesia moderna, agora eleva-se como ponto de convergência das buscas fundamentais do poeta e do poema. Nesta visão, em que todo o olhar busca se ver e se conhecer, o texto poético funciona como um dínamo gerador de imagens e reflexos no horizonte textual, poético e humano. 
Observamos, então, no desenrolar-se desses três arquétipos míticos, que mito e modernidade se entrecruzam, se articulam dialeticamente na poesia de Murilo Mendes para que esta possa dar conta da autoconsciência desesperada do autor que busca incessantemente restaurar a poesia.

Com o eu muriliano estamos sempre diante de um ser a nos tornar interlocutores de seus desesperos e suas alegrias, de suas memórias e de suas esperanças, de suas tradições e de suas filosofias, abrindo um ardente espaço de troca no universo modernizado de homens divididos e de relações reificadas.

Assim, a expressão de todos esses elementos num universo poético, sob uma perspectiva mística-religiosa, oferece uma alternativa para o desolado quadro de falência das utopias da modernidade, posto que Murilo Mendes ordena em O Discípulo de Emaús: "recolhamos da tradição o que é espiritualmente vivo - e queimemos suas formas caducas".

\section{REFERÊNCIAS}

ARRIGUCCI, Davi. O escorpião encalacrado. São Paulo: Perspectiva, 1973. BRUNEL, Pierre (org.). Dicionário de mitos literários. Rio de Janeiro: José Olympio. 1977

CANDIDO, Antonio. Na sala de aula. São Paulo: Ática, 1989.

GUIMARÃES, Júlio Castanõn. Murilo Mendes: a invenção do contemporâneo. São Paulo, Brasiliense, 1986.

STEGAGNO, Luciana Picchio. (Sel. e org.). Murilo Mendes: Poesia Completa e Prosa. Rio de Janeiro, Editora Nova Aguilar, 1994. 